\title{
Definiendo al indígena salvadoreño
}

\author{
Jorge $E$. Lemus \\ Universidad Don Bosco • El Salvador • 2009
}

Difícil tarea la de definir a un pueblo que ha sido invisibilizado por muchos años y cuya existencia ha sido negada o considerada un problema por las autoridades y por la sociedad en general. Ya lo decía Ralph Ellison en su novela Invisible Man (1952) refiriéndose a los negros en los EE.UU., la sociedad sabe que están allí, pero prefiere no mirarlos. Son invisibles porque no existen como personas, por lo que sus problemas no son los problemas de la sociedad. Igualmente, los indígenas salvadoreños han sido borrados de la memoria de los salvadoreños de tal suerte que muchos cogen con gran sorpresa la noticia de que en El Salvador hay indígenas y que aún se habla una de las lenguas ancestrales, el náhuat o pipil. Los indígenas salvadoreños han sido sistemáticamente destruidos como pueblo y absorbidos por la cultura dominante. Lo indígena es visto como algo folclórico, de potencial interés para turistas, pero no como algo propio. Los "indios" son solo parte de la historia que superficialmente se estudia en la escuela; sus aspiraciones, sus problemas y, en general, su condición humana, no son del interés de la sociedad en general y del estado en particular. Esta concepción está tan arraigada en el imaginario colectivo de los salvadoreños que los mismos indígenas niegan su identidad y quieren ser parte de la sociedad dominante, la ladina. En este artículo propongo algunos criterios básicos que pueden ayudar a definir e identificar de mejor manera al indígena salvadoreño, sin pretender que estos criterios sean exhaustivos. Primero, establezco la existencia de indígenas en El Salvador, en un intento de visibilizarlos $\mathrm{y}$, así, refutar la tesis que sostiene que no hay indígenas en el país. Luego, discuto la aplicación a los indígenas salvadoreños de algunos criterios universales propuestos en la literatura para definir a los grupos étnicos. A continuación, reviso algunas propuestas hechas para caracterizar al indígena salvadoreño, señalando la validez o no de las mismas. Finalmente, propongo ocho características para definir a los indígenas salvadoreños.

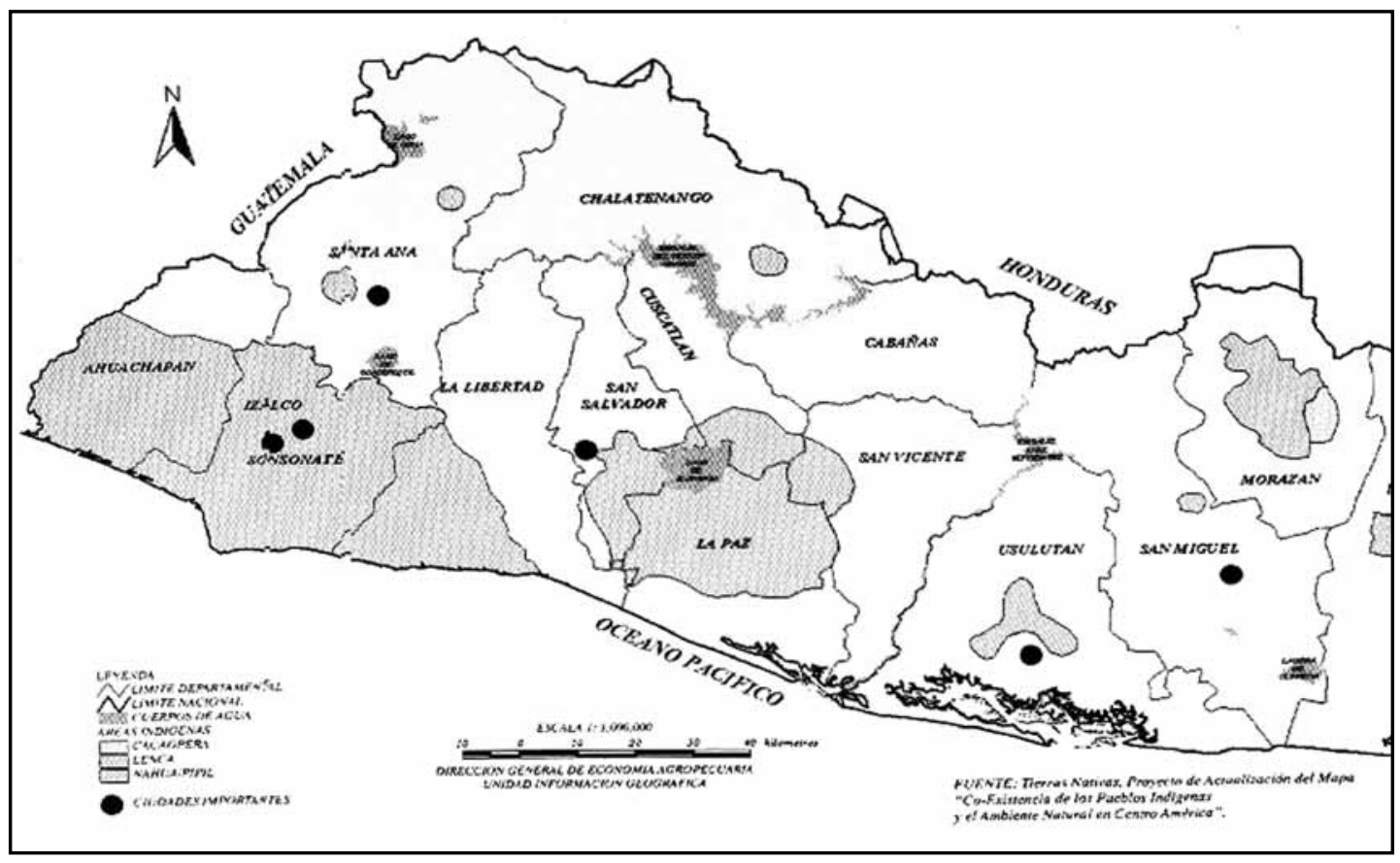

\section{Figura 1}

Mapa de El Salvador señalando los asentamientos indígenas del país. Fuente: Tierras Nativas. Proyecto de Actualización del Mapa "Co-Existencia de los Pueblos Indígenas y el Ambiente Natural de Centro América". (CONCULTURA 2003) 


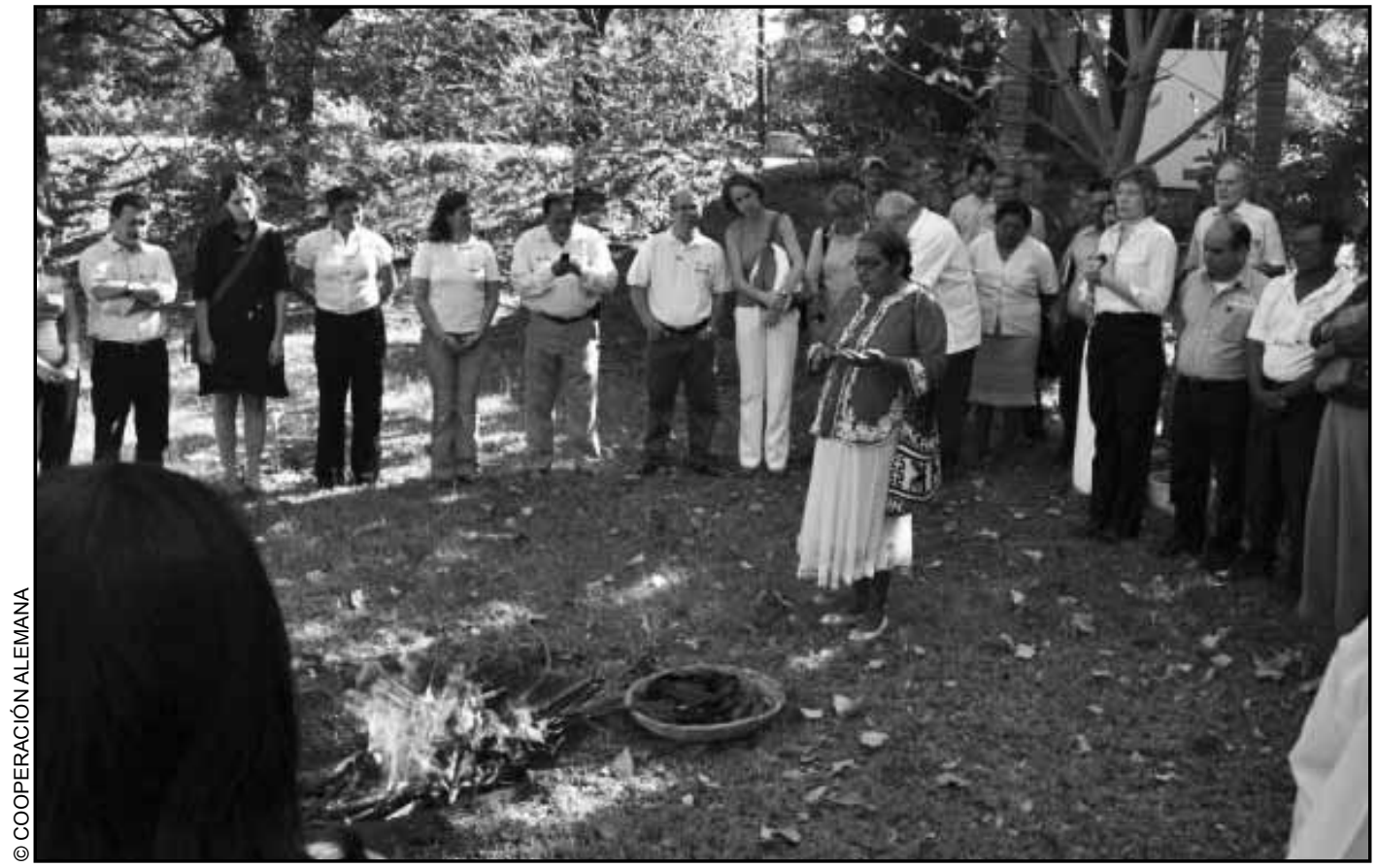

Ceremonia de indígenas centroamericanos. Enero 2010.

\section{Persistencia indígena}

Una de las preguntas que recibo con mayor frecuencia cuando hablo en público sobre la problemática indígena del país es ¿Qué todavía hay indios en El Salvador? y, al contestarles afirmativamente, la siguiente pregunta es ¿Y dónde están? Nadie puede dar cuenta de la existencia de algún grupo indígena en el país, y se sorprenden al decirles que existen al menos tres grupos étnicos distintos. Pero, ¿cómo sabemos que aún hay indígenas en el país? Hay al menos tres fuentes principales que corroboran la existencia de indígenas en el país. La primera son las fuentes oficiales. El Censo Poblacional 2007 (Dygestic 2008) encontró que el $0.02 \%$ de la población se definía como indígena, perteneciente a tres grupos étnicos: pipiles, lencas y cacaoperas ${ }^{1}$. También, el Consejo Nacional para la Cultura y el Arte (CONCULTURA 2003) establece la existencia de los tres grupos étnicos mencionados arriba y explora algunas de las características socio-culturales comunes a estos grupos étnicos con el fin de diferenciarlos del resto de la población.
En el mapa anterior podemos observar las áreas de concentración indígena en el país. El occidente y el centro del país son los que muestran la mayor concentración de comunidades con presencia indígena. Esta es la zona pipil histórica y la única que ha mantenido pequeños grupos de ancianos que hablan pipil o náhuat ${ }^{2}$ (ver Lemus 2008). El resto de pueblos indígenas señalados en el mapa están ubicados en el oriente del país, siendo los cacaoperas los más pequeños ${ }^{3}$, concentrados en la zona central del departamento de Morazán en el oriente del país. A continuación resumo la información general sobre las tres etnias aún existentes en el país:

\section{Lencas}

Poblaron el oriente del país (Usulután, San Miguel, Morazán y la Unión) y tenían como frontera natural el río Lempa, que los separaba de los pueblos pipiles. Los lencas salvadoreños, también conocidos como potones, dejaron de hablar su idioma a mediados del siglo pasado. No está clara la afiliación lingüística de esta lengua; para algunos es una

El mismo censo también señala la existencia de una comunidad negra en El Salvador. Esto es insólito ya que nadie jamás los ha identificado ni puede ubicarlos geográficamente. Este error evidencia algunas de las fallas en el diseño del censo.

2 Los hablantes de náhuat, según estimaciones propias, no sobrepasan los 200. El censo poblacional 2007 (Dygestic 2008) únicamente identifica a 97 hablantes.

3 Esta distribución geográfica contrasta con los datos poblacionales arrojados por el Censo 2007 que determina que el 31.3\% de la población indígena del país es cacaopera, mientras que los pipiles equivalen únicamente al 26.6\%. Esta simple observación pone en duda una vez más la validez del censo poblacional. 
lengua sin clasificar (Campbell 1976) y para otros es una lengua chibcha (Constenla 1981). Algunos topónimos en este idioma son Gotera "Cerro Alto", Guatajiagua "Lugar con cultivos de tabaco" y Perquín, "Camino de brasas o camino de carbones encendidos". La artesanía que identifica a esta zona es el barro negro. En la actualidad, la cultura lenca ha sido absorbida por la cultura ladina (i.e., mestiza) dominante, por lo que muy pocas personas se identifican como lencas o potones. Algunas asociaciones indígenas sí reivindican la cultura lenca (ver Tabla 2 más adelante).

\section{Cacaoperas}

Este es un grupo indígena pequeño que ha logrado sobrevivir hasta la actualidad. Habitan en las mismas zonas del departamento de Morazán y el norte de La Unión que habitaban antaño y, aunque su lengua ya está extinta, mantienen algunas tradiciones locales, como el famoso baile de los emplumados, que representa a la serpiente emplumada Xochiquetzal. El cacaopera, también conocido como ulúa, es una lengua misumalpa, emparentada con el miskito y el sumo de Nicaragua. Se hacen esfuerzos locales por mantener viva la identidad indígena, incluyendo la recopilación de algunos vocablos de esta lengua.

\section{Pipiles}

El pueblo pipil es un grupo indígena descendiente de emigrantes nahuas que llegaron a Centroamérica en diversas olas migratorias entre los años 800 y 1300 d.C., aproximadamente (ver Fowler 1989, Lemus 2004). En El Salvador, estos grupos poblaron el occidente y el centro del país, en donde desarrollaron una cultura propia y se convirtieron en la cultura dominante de la región. Su idioma, el pipil o náhuat, es la única lengua indígena que aún se habla en El Salvador.

La decadencia de los pueblos indígenas y sus lenguas es un proceso histórico que comenzó con la conquista española y que los ha llevado a punto de extinción. Los indígenas actuales son un grupo étnico de difícil definición, ya que el mestizaje y el sincretismo cultural los ha vuelto un grupo que pasa desapercibido, que se confunde a simple vista con el salvadoreño promedio, y más aún con los campesinos.

Tabla 1

Etnias Salvadoreñas

\begin{tabular}{|c|c|c|c|c|c|c|}
\hline $\begin{array}{l}\text { Grupo } \\
\text { étnico }\end{array}$ & Heteroglotónimo & Autoglotónimo & Familia & Población $^{4}$ & Ubicación geográfica & \# de hablantes \\
\hline Lenca & lenca & lenca, potón & $\begin{array}{l}\text { Clasificación indefinida. } \\
\text { Se propone que pertenece } \\
\text { a la familia Chibcha. }\end{array}$ & 1,735 & $\begin{array}{l}\text { Departamentos de } \\
\text { Usulután, San Miguel, } \\
\text { Morazán y La Unión }\end{array}$ & $\begin{array}{l}\text { Sin hablantes } \\
\text { Lengua extinta }\end{array}$ \\
\hline Cacaopera & cacaopera, ulúa & kakawira & Misumalpa & 3,596 & $\begin{array}{l}\text { Departamento de } \\
\text { Morazán y norte del } \\
\text { Depto. de La Unión }\end{array}$ & $\begin{array}{l}\text { Sin hablantes } \\
\text { Lengua extinta }\end{array}$ \\
\hline Pipil & $\begin{array}{l}\text { pipil/náhuat, } \\
\text { también a las } \\
\text { tribus pipiles que } \\
\text { se encontraban en } \\
\text { los departamentos } \\
\text { de San Vicente } \\
\text { y La Paz se les } \\
\text { conoce como los } \\
\text { "nonualcos" }\end{array}$ & nahua & Uto-Azteca & 3,056 & $\begin{array}{l}\text { Pequeños grupos } \\
\text { esparcidos en el } \\
\text { occidente y centro del } \\
\text { país, especialmente } \\
\text { en el departamento } \\
\text { de Sonsonate, y } \\
\text { grupos aislados en } \\
\text { los departamentos de } \\
\text { Ahuachapán, Santa } \\
\text { Ana, La Libertad, San } \\
\text { Salvador, Cuscatlán, } \\
\text { San Vicente y La Paz. }\end{array}$ & $\begin{array}{l}\text { Aproximadamente } \\
200 \text { ancianos } \\
\text { Lengua en } \\
\text { severo peligro de } \\
\text { extinción }\end{array}$ \\
\hline
\end{tabular}

$4 \quad$ Según el Censo Poblacional 2007 publicado por el gobierno de El Salvador (Dygestic 2008). Estos números han sido duramente criticados por académicos y asociaciones indígenas ya que según cálculos propios las poblaciones indígenas son mayores. 
Las características externas encontradas en otras etnias, tales como la vestimenta y la lengua dejaron ya hace mucho tiempo de ser rasgos distintivos de los indígenas salvadoreños. Es por este motivo que los indígenas han sido invisibilizados por la sociedad salvadoreña en general; por lo que para muchos, los grupos indígenas y sus lenguas vernáculas ya no existen en el país. Sin embargo, como lo muestra el mapa en la Figura 1, aún existen regiones en el país con presencia indígena.

La segunda evidencia de la existencia de grupos indígenas en El Salvador proviene de las organizaciones indígenas existentes en el país. Existen más de 25 ONG's indígenas activas en el país (ver Tabla 2). Estas están formadas por grupos indígenas y culturales que buscan reivindicar la causa indígena. Algunos de los miembros de estas asociaciones se identifican como indígenas, aunque su ascendencia no está claramente definida. Son personas que se han identificado con la causa indígena. Podríamos llamarlos "neo-indígenas", aunque su cultura es enteramente ladina, y las diferentes etnias no reconocen como indígenas a muchos de los miembros de estas asociaciones.

Tabla 2

Asociaciones Indígenas de El Salvador ${ }^{2}$

\begin{tabular}{|l|}
\hline 1. Alcaldía del Común de Izalco \\
\hline 2. Asociación Coordinadora de Comunidades Indígenas de El Salvador, ACCIES \\
\hline 3. Asociación Cultural Indígena de Cuscatlán. ACIC \\
\hline 4. Asociación de Comunidades Lenca de Guatajiagua, ACOLGUA \\
\hline 5. Asociación de Desarrollo Comunal Indígena Náhuat, ADESCOIN \\
\hline 6. Asociación de Pueblos Indígenas Mayas de Cuscatlán, APIMAYCO \\
\hline 7. Asociación de Rescate Cultural, ARCO \\
\hline 8. Asociación de Trabajadores Agrícolas Indígenas Salvadoreños, ADTAIS \\
\hline 9. Asociación Nacional de Indígenas Salvadoreños, ANIS \\
\hline 10. Asociación Nacional Indígena de El Salvador. ASNAIS \\
\hline 11. Asociación Nacional Indígena Tierra Sagrada, ANITISA \\
\hline 12. Asociación para el Rescate de la Cultura Ancestral, ARCAS \\
\hline 13. Comunidad Indígena de Cacaopera \\
\hline 14. Comunidad Lenca de Chilanga \\
\hline 15. Comunidad Lenca de Guatajiagua \\
\hline 16. Comunidad Lenca de San Simón \\
\hline 17. Consejo Coordinador Nacional Indígena Salvadoreño, CCNIS \\
\hline 18. Consejo de Ajquijab Maya de Occidente \\
\hline 19. Consejo Nacional Indio Salvadoreño, CONAIS \\
\hline 20. Consejo Ukarsukulwa Warrima Kakawira \\
\hline 21. Instituto para el Rescate Ancestral Indígena Salvadoreño, RAIS \\
\hline 22. Los Pasos del Jaguar \\
\hline 23. Movimiento Autóctono Indígena Salvadoreño, MAIS \\
\hline 24. Movimiento Indígena de la Mujer (SIHUAT) \\
\hline 25. Movimiento Indígena Nonualquense, MIN \\
\hline 26. Nuevo ANIS (Consejo de Ajquijab) \\
\hline
\end{tabular}




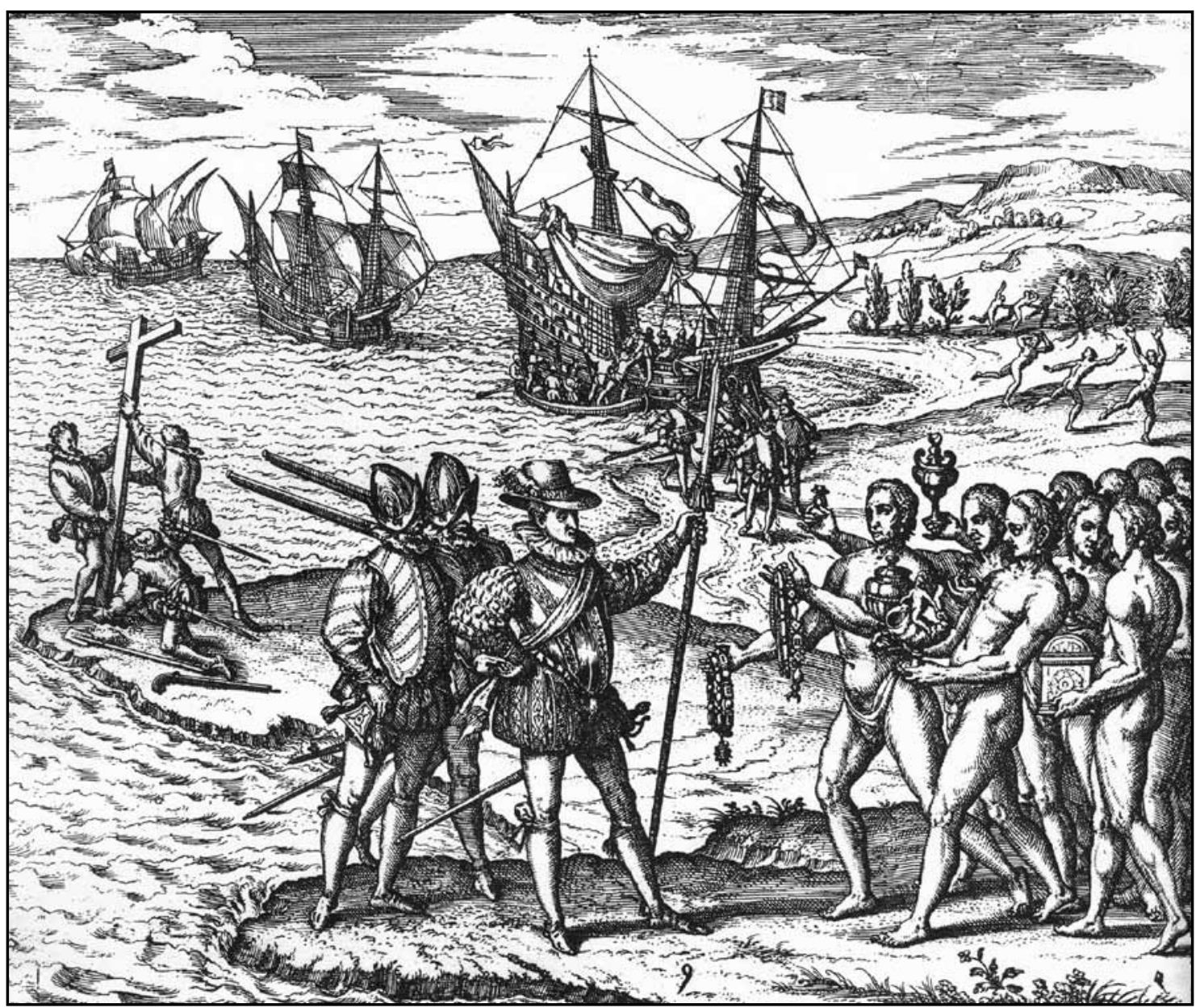

La tercera evidencia son los indígenas mismos que mantienen sus costumbres y viven en comunidades rurales, practicando, la mayoría, la misma agricultura de subsistencia y la orfebrería que han practicado por cientos de años. Muy pocos mantienen su lengua ancestral, pero muchos más mantienen su identidad. Su persistencia como grupo étnico, a pesar de la barbarie de la colonia y la conquista, la persecución, represión y discriminación de que han sido objeto, es admirable. Los indígenas salvadoreños aún existen, aunque su presencia siga siendo invisibilizada.

\section{¿Qué es un grupo étnico?}

Para comenzar la discusión sobre la definición de los grupos indígenas de El Salvador es necesario establecer un marco teórico que nos ayude a definir con la mayor exactitud posible a un grupo étnico. Diversos antropólogos (Barth 1969, Smith 1986) han establecido criterios para la definición de un grupo étnico. En general, un grupo étnico se puede definir como un grupo de personas que se identifican a sí mismas como individuos que comparten rasgos culturales, lingüísticos, religiosos, conductuales y biológicos, de tal manera que forman un grupo distinto a otros. Barth (1969:10-11) ${ }^{4}$ sostiene que un grupo étnico:

1. en gran medida, se autoperpetúa biológicamente,

2. comparte valores culturales fundamentales, desarrollados con unidad manifiesta en formas culturales,

3. integra un campo de comunicación e interacción,

4. sus miembros se identifican a sí mismos y son identificados por otros como constituyentes de una categoría distinguible de otras categorías del mismo orden. 


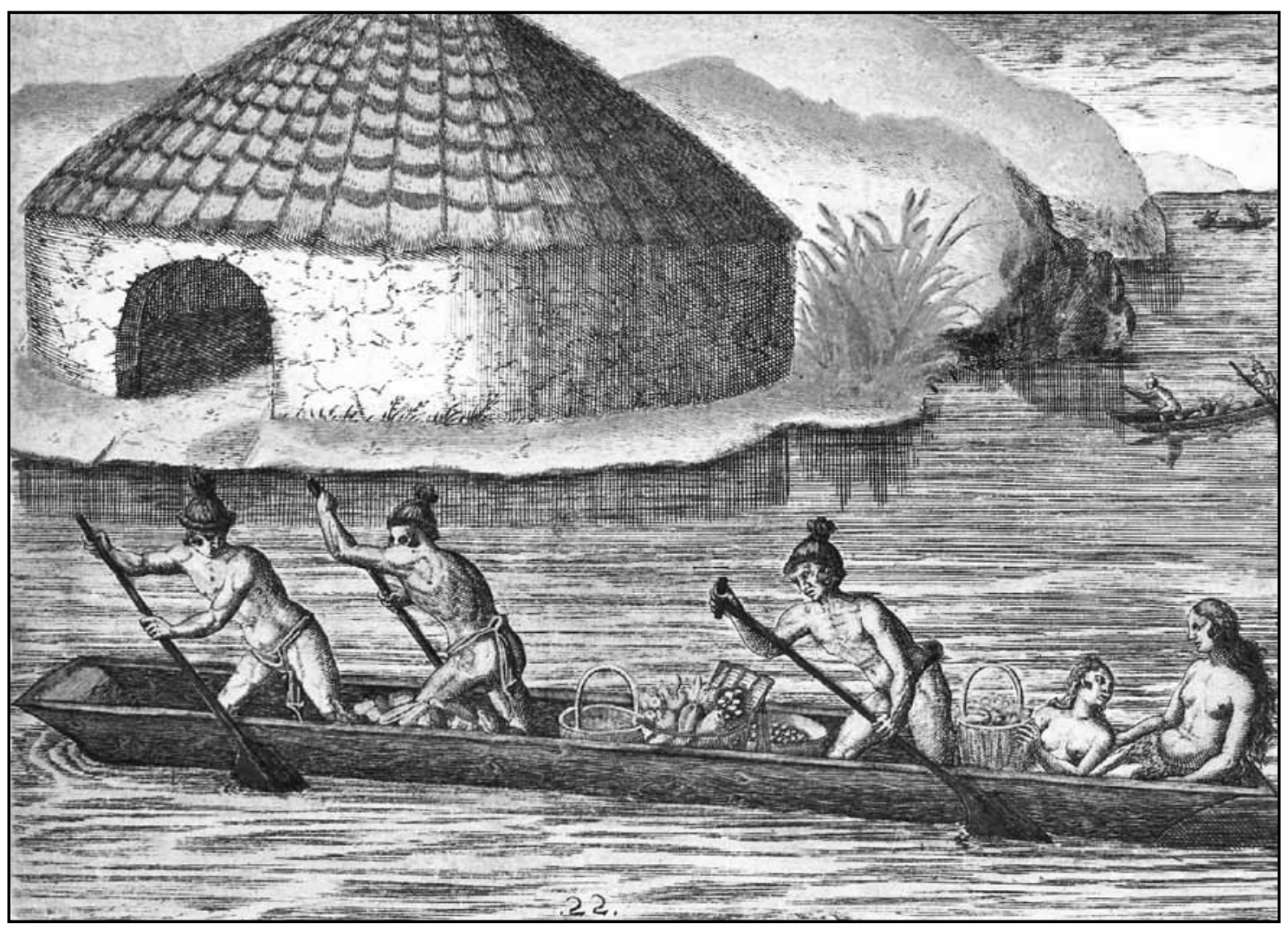

Estas características genéricas pueden utilizarse para definir a los indígenas salvadoreños con cierta exactitud, aunque dejan fuera algunas características propias de nuestros indígenas. Las uniones interétnicas han sido comunes en el país desde la colonia. El mestizaje en El Salvador es prácticamente total, por lo que es casi imposible diferenciar a un indígena de un ladino. En las comunidades en las cuales aún existen asentamientos significativos de indígenas, como Santo Domingo de Guzmán, las uniones interétnicas son comunes. En el resto del país, ese no es tan siquiera un tema de discusión. Por lo tanto, la perpetuación biológica de los indígenas salvadoreños no se puede tomar en la actualidad como un indicador de pertenencia al grupo étnico. Un paseo por el centro de San Salvador, o de cualquier ciudad o pueblo del interior del país, revela la imposibilidad de identificar a los indígenas de los no indígenas. Este hecho hace que la característica 1 de Barth no aplique a los pipiles.

Como grupo, los indígenas salvadoreños mantienen valores culturales propios tales como su vínculo con la tierra, la división de tareas en la familia, la religiosidad y la solidaridad de grupo. Las mujeres indígenas trabajan las artesanías, especialmente la orfebrería, cuidan de sus hijos y maridos. Los hombres trabajan el campo. La mayoría de indígenas pertenecen a una cofradía y son devotos católicos. Sin embargo, hay un grupo cada vez más numeroso de indígenas que se congregan en iglesias evangélicas, las cuales se han multiplicado casi exponencialmente en todo el país. Por ejemplo, según Lara (2006:67), la población católica de Santo Domingo de Guzmán, municipio del departamento de Sonsonate, es ahora sólo el $43.1 \%$, mientras que los evangélicos representan el $46.55 \%$ de los habitantes del pueblo, y un $10.35 \%$ declara que no pertenece a ninguna denominación religiosa. Este dato es interesante porque en la década de 1980, sólo existían dos iglesias evangélicas en el pueblo, mientras que ahora existen al menos $18^{5}$. Sin embargo, aún se puede afirmar que los indígenas manifiestan su espiritualidad participando activamente en una iglesia cristiana ( sin importar la denominación), pero que las cofradías siguen siendo una institución mayormente indígena en las comunidades que aún tienen presencia indígena. Son muy pocos los indígenas que practican religiones precolombinas. Los que lo hacen, practican religiones de origen maya y no pipil o azteca $^{6}$. Sin importar las preferencias religiosas se puede

Datos propios del autor, producto del trabajo de campo en la zona por más de veinte años.

6 Ver discusión más adelante sobre la mayanización de los indigenas salvadoreños. 
afirmar que los pipiles aún mantienen valores culturales comunes, como lo dicta la característica 2 de Barth.

Los ancianos pipiles aún mantienen un campo reducido de comunicación e interacción, a diferencia de los jóvenes $\mathrm{y}$ adultos, segunda y tercera generación, que han creado o se han incorporado a otras redes sociales fuera de la comunidad indígena. Es decir, no se puede definir un campo de comunicación e interacción exclusivo de los indígenas en las comunidades. Algunas ONG's como ACCIES, ANIS y CCNIS realizan actividades culturales pero no son espacios naturales de interacción y comunicación en las comunidades. Por lo tanto, tampoco se pude utilizar el criterio 3 de Barth para clasificarlos.

La característica 4 de Barth implica que no basta con autodefinirse como miembro de un grupo étnico; es necesario que los mismos miembros del grupo y miembros de otros grupos identifiquen a la persona como perteneciente a la etnia. Este es el caso de los neoindígenas salvadoreños aglutinados en las numerosas ONG's indígenas mencionadas anteriormente. Estas personas pertenecen a asociaciones autodenominadas indígenas, visten atuendos tradicionalmente relacionados con los indígenas, pero no todos son vistos como tales por los grupos indígenas ni por otros grupos sociales ${ }^{7}$. Genaro Ramírez ${ }^{8}$, pipil de Santo Domingo de Guzmán dice, al referirse a algunas personas de estas asociaciones: "Esos no son indios. No hablan la lengua y nunca han trabajado la tierra". Es interesante notar que los dos criterios utilizados por don Genaro son la lengua y el trabajo. La relación del indígena con la tierra es muy cercana. Muchos de los problemas sociales en el país tienen su origen en la distribución de la tierra. En la segunda mitad del S. XIX, el gobierno expropió las tierras comunales y ejidos que habían sido utilizados por generaciones por los indígenas y campesinos, según el Decreto Legislativo de marzo 2 de 1882, sumiéndolos en una total pobreza, al impedirles practicar su agricultura de subsistencia. Para sembrar sus cultivos tenían, y aún tienen, que arrendar las tierras para sus cultivos de subsistencia.

En general, entonces, los indígenas salvadoreños comparten dos de las características universales de Barth, ya que se reconocen a sí mismos y son reconocidos por otros como indígenas y además comparten valores y patrones culturales propios de sus etnias. Comparten valores como la solidaridad de grupo, la religiosidad, el vínculo con la tierra y la superstición. Además, aunque no todos los indígenas actuales hablan su lengua, todos conocen algo de ella. En todas las comunidades hay indígenas que niegan tener conocimiento del idioma autóctono, pero comprenden palabras y frases, y en el ambiente apropiado de confianza, entre ellos mismos, son capaces de interactuar con sus congéneres con una combinación de español y frases nahuas. He descubierto en las comunidades, jóvenes de veinte años que tienen conocimientos del idioma. De hecho, uno de los colaboradores del proyecto de revitalización ${ }^{9}$ que impulsa la Universidad Don Bosco, Carlos Cortez, es uno de estos jóvenes. Dentro del proyecto ha recuperado su lengua y ahora es un hablante fluido de náhuat y profesor de la lengua.

Otro intento de definir a los grupos indígenas lo hace Masferrer (1981), quién considera al menos tres niveles de identidad. El primero, es el sociocultural, que requiere que la persona sea miembro activo de una comunidad indígena. Esto es similar a lo planteado por Barth en el sentido de que la comunidad tiene que reconocerlo como su miembro y portador de la cultura de ese grupo indígena. El segundo criterio lo toma de la Oficina de Asuntos Indígenas de los EE.UU. (Bureau of Indian Affairs). El BIA (por sus siglas en inglés) requiere que toda persona que se autodenomine indígena compruebe que al menos el $25 \%$ de su sangre es indígena. Esto significa que debe demostrar que al menos uno de sus padres o abuelos era indígena. Este es un criterio legal solamente aplicable si en el registro civil se asientan los niños como indígenas, o se especifica en las partidas de nacimiento la etnicidad de los padres. En los Estados Unidos, éste es un criterio importante debido a los beneficios a los que las comunidades indígenas tienen derecho a manera de indemnización por las tierras que les fueron quitadas desde la conquista y colonia hasta el siglo pasado. El tercer criterio de Masferrer tiene que ver con la ascendencia comprobada. Es decir, la persona tiene que demostrar que desciende de indígenas. Si una persona ya es reconocida como indígena es suficiente prueba para demostrar que sus descendientes también lo son.

\footnotetext{
Esta afirmación no es una generalización. Hay indígenas en algunas de estas organizaciones (como ACCIES, CCNIS y ANIS) que tienen una ascendencia indigena comprobada y son portadores de la cultura de su etnia. El comentario que sigue de Genaro Ramírez es también una afirmación con respecto a algunos miembros de estas organizaciones y no a todos en general.

8 Comunicación personal. Ramírez es líder indígena, director de la Casa de la Cultura de Santo Domingo de Guzmán en el departamento de Sonsonate, náhuat-hablante y autor de publicaciones sobre la lengua náhuat-pipil.

9 Ver Lemus 2008 para una descripción detallada del proyecto de revitalización de la lengua náhuat o pipil de El Salvador.
} 
El criterio sociocultural y el de descendencia aplican a los indígenas salvadoreños. Los indígenas son receptores y transmisores de su cultura y se reconocen entre ellos. En cualquier comunidad en la cual aún hay indígenas, éstos se identifican entre ellos. También todos pueden hablar de sus padres y parientes indígenas, e incluso identificar quiénes hablaban la lengua y quiénes no. Esto se debe a que la última generación de indígenas, sobrevivientes de la masacre de 1932, aún reconocen su etnicidad y la de sus descendientes. La sangre indígena es difícil de comprobar en El Salvador en el presente, ya que las partidas de nacimiento no mencionan el grupo étnico de los niños ni de sus padres. A principios del siglo pasado, sin embargo, esta práctica aún persistía en algunas poblaciones, por lo que es posible encontrar ancianos con partidas de nacimiento que mencionen su origen étnico.

\section{Intentos de definición del indígena salvadoreño}

Existen dos estudios frecuentemente citados en la literatura indígena salvadoreña que hacen referencia a la identidad de estos pueblos. El primero de estos estudios es el del antropólogo/sociólogo salvadoreño Alejando Marroquín (Marroquín 1975), quién define a los indígenas salvadoreños desde un punto de vista socioeconómico, afirmando que los indígenas de El Salvador son "descendientes de los primeros pobladores de América, que por efectos de la conquista ibérica fueron reducidos a condiciones de aguda explotación, miseria, opresión e injusticia social, condiciones que, en lo esencial, se mantienen en dichos descendientes". Esto lo confirman los indicadores de desarrollo del país publicados por organismos internacionales como la OPS (1999) y el PNUD (2003), los cuales demuestran que, en general, las poblaciones identificadas como indígenas, tienen niveles de desarrollo por debajo del promedio nacional. El Mapa de Pobreza publicado por el organismo gubernamental FISDL $^{10}$, muestra que 32 municipios se encuentran en el nivel de pobreza extrema severa. Estas son personas que tienen ingresos menores a US\$1 al día. Entre estas comunidades se encuentran los mayores asentamientos indígenas del país, tales como Santo Domingo de Guzmán, considerado el mayor asentamiento indígena del país y donde se concentra el mayor número de hablantes de náhuat/pipil, Cuisnahuat, el segundo municipio con mayor presencia indígena, Caluco, Masahuat, y otros municipios del departamento occidental de Sonsonate, al igual que municipios del oriente del país, como Cinquera, Guatajiagua y Torola, considerados asentamientos de las etnias lenca y cacaopera.

Aunque la pobreza golpea con mayor fuerza a las comunidades indígenas, dentro de ellas viven personas (la mayoría) que no son indígenas o no se identifican como tales. Esto desvirtúa el criterio de pobreza ya que hay demasiados pobres en el país, en todas las regiones geográficas, y no todos ellos son indígenas. Por lo tanto, el criterio socioeconómico puede aplicarse a los indígenas, pero acompañado de otros criterios que ayuden a discriminarlos mejor.

El otro trabajo frecuentemente citado es el del antropólogo estadounidense Mac Chapin (1991), quien hace referencia a cinco aspectos que él considera definen al indígena salvadoreño. Primero plantea un aspecto biológico como determinante; sostiene que el color de piel distingue a los indígenas de los demás grupos sociales. Los indígenas, según él, tienen el color de piel más oscuro que el resto de la población. Este enfoque biologista es rápidamente refutado al comparar el color de piel de los indígenas y los ladinos ${ }^{11}$. Se encuentran en el país tonalidades que las personas describen como moreno oscuro, moreno claro, trigueño y blanco. En las comunidades indígenas se encuentran de todas las tonalidades. El otro criterio utilizado por Chapin coincide con el de Marroquín discutido anteriormente al considerar la pobreza y el trabajo pesado como determinantes de los grupos indígenas. Los mismos argumentos planteados arriba al criterio socioeconómico de Marroquín aplican a Chapin. El mapa de pobreza del país es demasiado extenso.

Chapin también considera el idioma como rasgo de identidad indígena. En realidad, sí es un rasgo determinante: las personas que aún hablan pipil, ya no hay hablantes de lenca ni cacaopera, son, indiscutiblemente, indígenas. Pero igual, hay muchas más personas que no hablan ninguna lengua indígena pero que, incluso en las comunidades, son consideradas indígenas por los demás. Por lo tanto, este es un criterio demasiado excluyente. La lengua pipil, única lengua indígena hablada en El Salvador, está al borde de la extinción (UNESCO 1996, Lemus 2004, 2008). En vista de esto, Chapin aclara,

\footnotetext{
${ }^{10}$ Disponible en el sitio del Fondo de Inversión Social para el Desarrollo Local (FISDL): http://www.fisdl.gob.sv/content/view/58/103/

${ }^{11}$ Entendiendo a ladino como a cualquier persona que ha abandonado sus costumbres indigenas y ha adoptado las costumbres $y$ valores del grupo social dominante.
} 
citando a la antropóloga salvadoreña Concepción Clará de Guevara, que no es necesariamente náhuat lo que hablan, sino español con cierto acento peculiar, diferente a como lo habla el resto de la población; hacen uso diferente de los pronombres, el género de las palabras y los artículos. No explica ni ilustra ninguna de estas diferencias. Esta también es una generalización demasiado amplia en la actualidad, ya que el acento que Chapin y Clará llaman "particular" es el acento de campesinos, especialmente en los alrededores de Panchimalco, otrora importante asentamiento pipil.

Debido al bajo estatus de los indígenas en El Salvador, la mayoría niega su identidad y prefieren ser llamados ladinos. Esto hace que el indígena tenga baja autoestima, y se considere a sí mismo inferior al resto de la población. Chapin recoge esta concepción y propone la autoestima baja como característica de los indígenas. La baja concepción de los indígenas, perpetuada en expresiones estereotipadas utilizadas por la población en general, como "se te salió el indio", "dejate de indiadas" e "indio bruto", ha sido internalizada por los indígenas al punto de creerse a sí mismos inferiores. La baja autoestima sigue siendo una característica de los indígenas, impuesta a ellos por la sociedad a través de la historia. Recientemente, entrevisté a algunos indígenas en Santo Domingo de Guzmán, para conocer cómo se autodefinen. Para ellos la pobreza, la vestimenta y el habla se repiten como características propias de los indígenas. A continuación, transcribo algunas de sus autodefiniciones:

"Viene de la naturaleza (del indígena) ser pobre, todo eso es cosa que así es, pues" (Leandro)

"La voz sí cambia...pero el vestuario es lo mismo, no cambia" (Cristina)

"practica sus raíces, su cultura, sus costumbres" (Esmeralda)

Por último, Chapin considera la religiosidad como característica principal de los indígenas. Como ya lo mencioné anteriormente, las cofradías siguen siendo el núcleo organizativo de preferencia en las comunidades indígenas, aunque muchos ahora asisten a iglesias evangélicas. Las religiones precolombinas no son practicadas más que por un pequeño grupo de personas que han estudiado las religiones mayas en Guatemala y que se denominan "sacerdotes mayas".

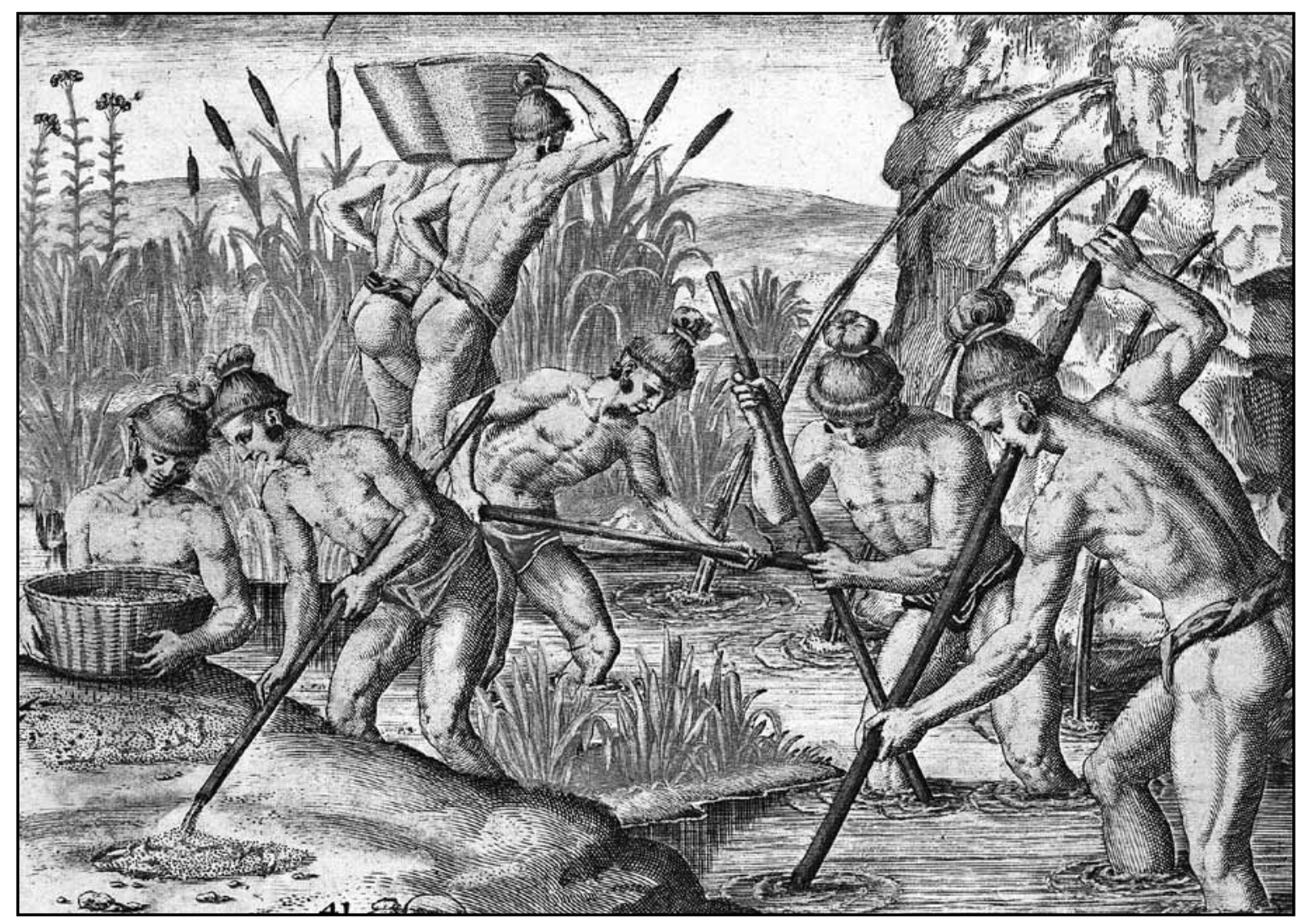


La discusión anterior deja claro que no es posible definir al indígena salvadoreño utilizando criterios aplicables a otras etnias debido al estado moribundo de la cultura indígena, la cual se ha mezclado enteramente con la cultura campesina del país, y la falta de características manifiestas únicas como lengua, vestuario, costumbres, ritos y rasgos físicos. Esto se debe al sincretismo cultural iniciado después de la Conquista y al mestizaje indiscriminado que tuvo lugar en el país desde la colonia hasta nuestros días. El indígena de la conquista ya no existe. La cultura indígena actuaúl es diferente a la cultura precolombina y la colonial. De hecho, la persecución y represión sistemática de que fueron objeto los indígenas después de los levantamientos de 1831 y 1932 aceleraron el proceso de asimilación a la clase dominante y el abandono de las costumbres que aún prevalecían entre la población indígena. Esto ha creado una pobreza cultural y una negación de todo lo indígena.

\section{Viendo hacia el norte: los mayas}

Después de la firma de los acuerdos de paz en Chapultepec, México, en 1992, que pusieron fin a la sangrienta guerra civil que sufrió El Salvador en los 1980's, las fuerzas sociales que carecían de representación civil se organizaron en numerosas organizaciones no gubernamentales. Esto también sucedió con los indígenas y, de contar con solo una organización reconocida, la Asociación Nacional de Indígenas Salvadoreños (ANIS) en los años 1980's, ahora existen alrededor de 26 ONG's que se autodenominan indígenas, cuyo accionar es variado (ver Tabla 2). Muchas de ellas, sin embargo, reivindican la cultura maya y no las culturas pipil, lenca o cacaopera. Es decir, ningún grupo indígena actual en el país es maya ${ }^{12}$, sin embargo, algunas asociaciones dicen representarlos a ellos.

La cultura maya de nuestros vecinos del norte, Guatemala y Honduras, es una cultura viva y diversa. Ellos cuentan con una presencia indígena superior en número y variedad étnica que la nuestra. El haber negado la cultura pipil durante por lo menos sesenta años (desde la masacre de 1932 hasta los Acuerdos de Paz en 1992), hizo que muchos tomaran como referencia la cultura maya, iniciando lo que llamo una "mayanización" de El Salvador. Esta mayanización se manifiesta de diversas maneras. Por un lado, oficialmente, el gobierno hace referencia a la cultura maya en sus programas e impulsa proyectos de desarrollo como "La Ruta Maya", que hacen énfasis en los vestigios arqueológicos mayas del país y utiliza glifos y otros símbolos mayas para promover el turismo, incluyendo el uso de motivos mayas en el Aeropuerto Internacional de El Salvador. Se realizan rituales mayas al inicio de algunos actos oficiales de CONCULTURA y el Ministerio de Educación. En general, el salvadoreño promedio reconoce a los mayas y su cultura como propias de El Salvador, al grado que muchos que reconocen a los pipiles, los consideran mayas también. Por otro lado, muchas ONG's indígenas han adoptado lo maya como propio, incluso en sus nombres (ver tabla 2), pero especialmente en el discurso público. Varios salvadoreños, incluso de comunidades alejadas de la cultura maya guatemalteca como Cacaopera, han recibido formación religiosa maya y se han convertido en sacerdotes mayas. Estos sacerdotes mayas realizan sus rituales en lenguas hayenses como el quiché y el cachiquel y promueven la cultura maya en el país. Esto ha creado una tremenda confusión sobre los orígenes de los indígenas salvadoreños y ha creado la imagen de El Salvador como territorio maya.

La razón por la cual esta mayanización no ha sido cuestionada, al contrario, ha sido promovida, incluso por los indígenas mismos, es el rompimiento brusco con la identidad indígena salvadoreña ocurrido después de la matanza de 1932. Las generaciones nacidas después de 1932 no fueron receptoras de la cosmovisión pipil, lenca o cacaopera, sino de una nueva visión del mundo producto del abandono de todo lo indígena y la integración total a la cultura dominante no indígena. Aún hay ancianos que se identifican como indígenas, pero la segunda y tercera generación ya no. Con el renacimiento de la causa indígena en la década de 1990, y ante la falta de una identidad propia indígena, se llenó ese vacío de identidad con la fuerte cultura maya de nuestros vecinos indígenas más cercanos: el pueblo maya guatemalteco. Esta adopción de la cultura maya también se ve reforzada por la existencia de vestigios arqueológicos de origen maya de los períodos preclásico y clásico tardío (Ohi 2000) como Tazumal, Casa Blanca, Joya de Cerén y San Andrés. A partir del siglo VIII d.C., sin embargo, toda la zona maya salvadoreña fue repoblada paulatinamente por los migrantes pipiles, de origen azteca, que vinieron en numerosas oleadas migratorias desde distintas regiones del sur de México, especialmente Soconusco y Veracruz, hasta el siglo XIII. Para el S. XIII, el occidente y centro de El Salvador estaban poblados por los pipiles y los pequeños grupos remanentes mayas dependían de éstos y les pagaban

${ }_{12}$ Durante la conquista y colonia, había grupos mayas pequeños en el occidente y norte del país. Sobresalian los pokomames y los chortís. Estos eran grupos que pagaban tributo a los cacicazgos pipiles. 
tributos. A la venida de los conquistadores, la mayor población y etnia dominante eran los pipiles. Sin embargo, la cultura pipil no construyó pirámides monumentales sino que ocupó algunas de las pirámides mayas para sus rituales. Entonces, la ascendencia étnica de los salvadoreños es mayormente pipil, pero los monumentos son originalmente mayas, por lo que es fácil identificarse con esta cultura y tomarla como propia, especialmente cuando la cultura pipil original dejó de transmitirse a las nuevas generaciones. Los bienes culturales tangibles como las pirámides son, además, un gran atractivo turístico, por lo que el apoyo gubernamental a través de CONCULTURA se centra en la excavación y mantenimiento de estos monumentos mientras descuida las manifestaciones culturales intangibles, incluyendo la lengua.

\section{Propuesta del perfil indígena salvadoreño}

Se ha demostrado en las páginas anteriores que los indígenas salvadoreños no se pueden definir sobre la base de criterios universales, como los propuesto por Barth, ni sobre la base de criterios regionales utilizados para definir a otras etnias, como los mayas. En esta sección propongo algunos criterios que pueden ayudar a definir al indígena salvadoreño. Hay que señalar que, a través de la historia, a los grupos indígenas no se les ha permitido organizarse, estudiar y conservar su lengua, practicar su religión ni desarrollarse como pueblo. Por lo tanto, no podemos exigir características claras para definirlos y tenemos que considerar cualquier aproximación a definirse como pueblo como válida. No son responsables los pueblos indígenas salvadoreños de haber sido transculturizados e invisibilizados a través de la historia. A continuación propongo ocho criterios para identificar a los indígenas salvadoreños y distinguirlos del resto de la población con la cual comparten numerosas características culturales.

Pobreza y movilidad social. Este es un tema recurrente en todos los estudios sobre los indígenas salvadoreños (Marroquín 1975, Chapin 1991, Lara 2006, Rivas 2004). Los indicadores de desarrollo del país muestran que las poblaciones indígenas se encuentran por debajo de la media nacional en aspectos como educación, salud, acceso a servicios públicos, etcétera. ${ }^{13}$ Además, los indígenas mismos se describen como muy pobres, peor que los demás, y lo consideran como una fatalidad incambiable por el solo hecho de haber nacido indígenas. Esto impide la movilidad social ya que "el indio nace pobre y muere pobre", con muy pocas posibilidades de subir en la escalera social. Entonces, se puede afirmar que éste es un criterio válido, y aunque el mapa de pobreza de El Salvador es extenso, los indígenas, a diferencia de otros grupos sociales, siempre están dentro de él, como uno de los grupos más empobrecidos del país. Salir del círculo de pobreza es prácticamente imposible para los indígenas. Aquellos, sin embargo, que han logrado prosperar, abandonan el pueblo $\mathrm{y}$, en adelante, niegan su ascendencia indígena.

Autoestima. La misma situación de pobreza extrema causada por las condiciones de desventaja social que han sufrido las poblaciones indígenas desde la conquista, han contribuido a bajar su autoestima y a considerarse menos que los demás. En la población en general, las referencias a lo indígena siempre son peyorativas. Los indígenas organizados han superado esta características y recuperado parte de su orgullo como grupo étnico. El resto, sin embargo, mantiene una baja autoestima y no siente orgullo de su ascendencia étnica.

Lengua. Se ha demostrado en varios estudios (Campbell 1985, Lemus 2004) y en los censos nacionales (DYGESTIC 2008), que la única lengua que cuenta con hablantes en El Salvador es el pipil o náhuat. Ésta no ha sido transmitida por al menos dos generaciones por lo que los únicos que la hablan son los ancianos abuelos. Sin embargo, en mi trabajo de campo he comprobado que las "generaciones perdidas" conocen algo de la lengua, entienden frases y palabras, pero son incapaces de interactuar en náhuat. Esto implica, que, al menos entre los pipiles, la lengua puede ser un criterio válido para definirse como pueblo. Es decir, todos aquellos que interactuaron cuando niños con familias pipiles, tienen un conocimiento pasivo de la lengua náhuat y, con poco esfuerzo, podrían convertirse en hablantes. Prueba de ello es Carlos Cortez, mencionado anteriormente, quien pasó de hablante pasivo a hablante activo y productivo en la lengua con unas pocas lecciones en el marco del proyecto de revitalización de la lengua náhuat que dirijo. Entre los lencas y cacaoperas también hay personas que recuerdan algunas palabras y frases en sus respectivos idiomas. Éstos son, desafortunadamente, muy pocos. Por lo tanto, el conocimiento de una lengua indígena a cualquier nivel se puede tomar como un factor determinante de pertenencia al grupo étnico.

Vestimenta. El conocido refajo de las mujeres indígenas todavía se puede ver en los pueblos y se puede utilizar para identificar a los indígenas de los no indígenas. Las mujeres

13 Ver Lemus (2008) para más detalles y los estudios de OPS (1998) y el PNUD (2003) y las estadísticas del FISDL. 
indígenas portan con orgullo su refajo, aunque ahora éstos son difíciles de conseguir debido a su elevado precio y a que no son producidos localmente, sino que tienen que importarse de Guatemala. Generalmente, en sus casas, las mujeres permanecen descalzas y al salir usan "caites" o sandalias de cuero. Los hombres se visten como cualquier campesino. Para trabajar en el campo, los hombres usan una camisa blanca de manta llamada cotón, sombrero, cebadera y tecomate ${ }^{14}$. La cebadera y el tecomate son dos prendas importantes para los campesinos también, ya que en ellas se porta la comida y la bebida en el campo.

Religiosidad. La religiosidad es otro aspecto mencionado recurrentemente cuando se describe al indígena salvadoreño. Como mencioné anteriormente, la única unidad organizativa con que contaban los pueblos indígenas era la cofradía, la cual siempre estaba relacionada con un santo. Esta libertad de reunión se volvía sumamente atractiva para los indígenas no solo como una oportunidad para incluir en el rito católico algunos rituales indígenas, sino también para discutir y buscar solución a algunos problemas propios de la comunidad. En la actualidad, debido al crecimiento de las iglesias evangélicas, muchos han abandonado las cofradías para participar en los cultos evangélicos. No obstante esta migración religiosa, los indígenas siguen siendo muy religiosos y supersticiosos. Aparte de los pocos que se han convertido en "sacerdotes mayas", los indígenas salvadoreños no practican religiones propias. Los ritos y deidades indígenas se han convertido en sustrato de los rituales católicos, produciendo una religión católica sincrética propia de la región.

Autodefinición. Por un lado, los indígenas de la generación de abuelos se identifican como tales y son capaces de identificar a otros, incluso a los más jóvenes que han abandonado todo vínculo con su etnia. En cada comunidad, cualquier indígena puede prácticamente recitar los nombres de los que son y los que no son indígenas. Las otras generaciones, hijos y nietos, se avergüenzan de su ascendencia indígena $\mathrm{y}$, generalmente, la niegan. Culturalmente, no se puede hablar de un grupo homogéneo que comparte valores, ideología y cosmovisión. Los más ancianos son la última generación que mantiene una identidad indígena compartida. Hablan la lengua, con diferentes grados de dominio, trabajan la tierra como antes, con herramientas propias, conocen las tradiciones, los mitos y las leyendas propias de sus regiones. Las siguientes generaciones han construido una nueva cultura con más rasgos campesinos que indígenas. Es decir, las nuevas generaciones han sido asimiladas por la cultura dominante y el único vínculo que mantienen con la cultura indígena son los abuelos. Se podría decir que subyace en ellos la cultura indígena, pero no la valorizan ni se identifican con ella.

Artesanías. En todas las viviendas indígenas se puede observar a las mujeres trabajando el barro para producir sus artesanías. En la zona pipil se producen comales ${ }^{15} \mathrm{y}$ ollas, principalmente, y otros productos de barro como macetas y adornos. En el oriente, en la zona lenca, se trabaja el barro negro. Los indígenas no utilizan torno para trabajar el barro. Las técnicas para trabajarlo son pasadas de una generación a otra y son exclusivas de los indígenas. Las mujeres ladinas no se dedican a hacer comales ni ollas. Los hombres trabajan la tierra, construyen los ranchos, hacen tapescos ${ }^{16} \mathrm{y}$ son los encargados, en su mayoría, de las transacciones comerciales. Estos conocimientos artesanales no están siendo transmitidos a las nuevas generaciones, por lo que, igual que la lengua, están en peligro de desaparecer en una generación.

Tradición oral. Gran parte de la riqueza cultural indígena aun subsiste en la tradición oral. Los mitos y leyendas pipiles, las historias fantásticas de los indígenas en las cuales ellos mismos son los protagonistas, la picardía presente en sus historias y las moralejas que ellas dejan son conocimientos compartidos por la población indígena y pasados de generación en generación. La última generación de ancianos ha transmitido estos conocimientos a sus hijos, pero de la generación de los nietos en adelante, esta transmisión se ha truncado. No todas las historias recopiladas por Schultze-Jena (1977) en los años 1930's, por ejemplo, son recordadas por los indígenas actuales.

Como se ha demostrado en este artículo, no es tarea fácil la definición de los indígenas. Hay que elaborar instrumentos

\footnotetext{
${ }^{14}$ La "cebadera" es un tipo de saco pequeño hecho de fibra de mezcal con un cinto para colgarla al hombro. Se utiliza especialmente para llevar comida al campo, aunque hoy se utiliza para portar otras cosas. Incluso, los estudiantes lo utilizan para llevar sus libros a la escuela. El "tecomate" es una especie de calabaza de corteza dura seca divida en dos por una especie de cintura y que se utiliza para llevar agua y otras bebidas como la chicha.

${ }^{15}$ Los "comales" son discos de barro que se utilizan para tostar semillas y hacer tortillas.

${ }^{16}$ Los "tapescos" son camas rústicas hechas de varas. Son comunes en todas las comunidades indígenas y también son utilizadas por los campesinos en general.
} 
adecuados, como cuestionarios y listas de cotejo, para poder determinar con bastante certeza si una persona es indígena o no. Los criterios anteriores son la guía para la construcción de dichos instrumentos. No basta una pregunta dicotómica para saber si es o no es indígena. Es necesario entrevistar a las personas para conocer su verdadera etnicidad.

De los criterios propuestos en esta sección, dos son exclusivos de los pueblos indígenas: el conocimiento de la lengua y la autodefinición. Los demás criterios, pobreza y movilidad social, religiosidad, tradición oral, autoestima y vestimenta son compartidos no solamente por los indígenas sino también por gran parte de la población salvadoreña. Por tal razón, los criterios se pueden dividir en criterios de primer orden (lengua y autodefinición) y criterios de segundo orden (los demás). Para ser considerado indígena hay que cumplir con los criterios de primer orden.

\section{Conclusión}

La problemática indígena salvadoreña es compleja. Involucra aspectos sociales, políticos y económicos de difícil solución debido al poco interés del estado y de la sociedad en general en los problemas de este grupo étnico minoritario. La condición de desventaja social señalada en este artículo y el abandono histórico forzado de su identidad hace que los indígenas salvadoreños se confundan con el resto de la población salvadoreña. Los intentos de caracterizarlos como grupo étnico se encuentran con el problema de la vaguedad de los criterios utilizados para definirlos ya que estos se traslapan con criterios aplicables también a la población salvadoreña en general. En este estudio se han considerado aspectos comunes de los indígenas que los caracterizan a ellos pero que también, individualmente, caracterizan a otros grupos sociales de El Salvador. Por lo que los criterios deben tomarse en conjunto, valorándolos según el grado de especificidad. Por ejemplo, un campesino puede cumplir con todos los criterios excepto la lengua y la autodefinición, mientras que un indígena puede cumplir únicamente con esos dos. Es decir, la autodefinición (y el reconocimiento de otros) como indígena es uno de los criterios más importantes y sin equa non para ser indígena. De igual manera, el conocimiento del náhuat (para los pipiles) a nivel conversacional o de solo frases y palabras sueltas parece ser también una característica sin equa non de los indígenas de la región occidental. En menor grado, son también importantes la pobreza y la poca movilidad social, la baja autoestima, la religiosidad y las demás características descritas en la sección anterior, pero éstas pueden ser compartidas por otros grupos sociales. El conocimiento de la fabricación de artesanías, especialmente el trabajo con el barro es también una actividad que parece estar restringida a las mujeres indígenas, aunque otros miembros de la comunidad pueden optar por aprender la técnica. En la zona pipil, sin embargo, nunca he visto ni a un hombre indígena ni a alguien de otro grupo social fabricando comales y ollas.

Las características de primer orden, lengua y autodefinición, son únicas de los indígenas, mientras que las demás pueden ser compartidas por otros grupos sociales. Las cofradías, por ejemplo, son dirigidas por ladinos en comunidades sin presencia indígena. La vestimenta del campesino es igual a la de los indígenas, así lo requiere el trabajo del campo. Sólo algunas mujeres indígenas portan refajo, el resto, especialmente las más jóvenes, no lo usan, igual que las ladinas. Por lo tanto, no se puede tomar el refajo ni ningún otra prenda de vestir como definitoria de la mujer indígena. También se demostró en el artículo que la pobreza y la poca o nula movilidad social no son condiciones exclusivas de los indígenas. De igual forma, la baja autoestima está presente en la mayoría de las personas de los estratos más pobres del país. Y, por último, los mitos y leyendas pipiles son ya parte del patrimonio cultural nacional y conocidos por todos los salvadoreños. Personajes como la Siguanaba, el Cipitío, el Cadejo, y otros tienen su origen en las historias indígenas, pero se han convertido en parte del saber colectivo de los salvadoreños. 


\section{Referencias}

Campbell, Lyle. 1985. The Pipil Language of El Salvador. Mouton, Berlin.

. 1976. The last Lenca. En International Journal of American Linguistics 42(1): 73-78.

. 1975. El estado actual y la afinidad genética de la lengua indígena de cacaopera. En La Universidad.

Revista de la Universidad de El Salvador. enero-febrero. pp 45-54

Chapin, Mac. 1991. La población indígena de El Salvador. En Mesoamérica 21. Antigua Guatemala, pp. 1-40.

CONCULTURA et al. 2003. Perfil de los Pueblos Indígenas de El Salvador. Ministerio de Educación, San Salvador.

Constenla Umaña, Adolfo. 1987. Elementos de Fonología Comparada de las Lenguas Misumalpas. En Revista de Filología y Lingüística de la Universidad de Costa Rica 13 (1), 129-161.

DIGESTYC. 2008. Censo de Población y Vivienda de El Salvador 2007, disponible en http://www.censos.gob.sv/

Duranti, Alessandro. 1997. Linguistic Anthropology. Cambridge University Press, Cambridge.

Fowler, William. 1985. Ethnohistoric sources on the pipil-nicarao of Central America: a critical analysis. En Ethnohistory 32(1):37-62

Fredrik Barth ed. 1969. Ethnic Groups and Boundaries: The Social Organization of Cultural Difference. Little Brown and Company, Boston.

Lara, Carlos B. 2006. La población indígena de Santo Domingo de Guzmán. Cambio y continuidad sociocultural. CONCULTURA, San Salvador.

Lemus, Jorge E. 2004. El pueblo pipil y su lengua. En Cientifica 5:7-28. San Salvador.

. 2008. Un modelo de revitalización lingüística. El caso del náhuat-pipil de El Salvador. En Identità delle Communità Indigene del Centro America, Messico e Caraibi: aspetti culturali e antropologici. IILA, Roma, pp. 127-149.

Marroquín, Alejandro. 1975. El problema indígena en El Salvador. En América Indígena XXXV-4, México.

Masferrer, Elio y Enrique Mayer. 1981. Identidad y aculturación. Réplica a Maletta. En América Indígena XLI-3, julioseptiembre, México, pp. 545-553.

Ohi, Kuniaki . 2000. Cronología tentativa del área de Casa Blanca. En Chalchuapa. Memoria Final de Investigaciones Interdisciplianrias de El Salvador. Universidad de Estudios Extranjeros de Kyoto.

OPS, CONCULTURA, CCNIS. 1999. Salud y calidad de vida de los pueblos indígenas en El Salvador. San Salvador.

PNUD. 2003. Informe sobre desarrollo humano. El Salvador 2003. Desafíos y Opciones en Tiempos de Globalización, PNUD y el Informe 262: Indicadores municipales sobre desarrollo humano y los objetivos de desarrollo del Milenio

Rivas, Ramón. 2004. Persistencia indígena en El Salvador. En Cientifica 5, pp. 29-49

Schulze-Jena, Leonhard. 1977. Mitos y Leyendas de los Pipiles de Izalco. San Salvador: Ediciones Cuscatlán.

Smith, Anthony D. 1986. The Ethnic Origins of Nations. Oxford: Blackwell.

UNESCO. 1996. Atlas of the World's Languages in Danger of Disappearing, UNESCO, Paris. 